\title{
The Effect of Substituted Phenoxyacetic and Phenoxybutyric Acids on the Growth and Respiration of Aspergillus niger
}

\author{
By J. E. SMITH AND J. L. SHENNAN \\ Department of Applied Microbiology and Biology, \\ University of Strathclyde, Glasgow, Scotland
}

(Received 12 July 1965)

\begin{abstract}
SUMMARY
Substituted phenoxyacetic and phenoxybutyric acids stimulated growth of Aspergillus niger at low concentrations $\left(10^{-6} \mathrm{M}\right)$ and inhibited growth at higher concentrations $\left(10^{-4} \mathrm{M}\right)$. The inhibition of growth was paralleled by an inhibition of endogenous and mitochondrial respiration. The main site of inhibition appears to be at that part of the respiratory chain which involves ubiquinone.
\end{abstract}

\section{INTRODUCTION}

Substituted $\gamma$-phenoxybutyric acids are used in agriculture for the control of dicotyledonous weeds in growing crops. Such selectivity apparently depends upon the conversion by $\beta$-oxidation of 4-chloro-2-methylphenoxybutyric acid (MCPB) to the active 4-chloro-2-methylphenoxyacetic acid (MCPA) within the tissues of susceptible weeds but not in the crop plants (Wain, 1955, 1957; Fawcett, Wain \& Wightman, 1960). It is inherent in this butyrate $\rightarrow$ acetate degradation concept that MCPB cannot be more toxic to plant life than MCPA.

Recently Shennan \& Fletcher (1965) have tested in vitro the effect of substituted phenoxy acids on the growth of selected species of bacteria, actinomycetes, fungi and micro-algae, and have shown that at low (herbicidal) concentrations there was no harmful effect on the micro-organisms. However, at concentrations greater than $10^{-4} \mathrm{M}$ there was a progressive increase in the toxicity of MCPB to most of the micro-organisms, whereas at similar concentrations MCPA had considerably less effect. These authors suggest that MCPB has in its own right an inherent protoplasmic toxicity at relatively high concentrations in addition to its hormonal effect at low concentrations when converted to MCPA. The present paper reports work done on the inhibitory action of high doses of MCPB and MCPA on the respiratory system of the filamentous fungus Aspergillus niger in an attempt to elucidate the site of the inhibition.

\section{METHODS}

Fungal material. The strain of Aspergillus niger van Tieghem used in this experimental work was obtained from the departmental stock cultures. Stock cultures of this fungus were maintained on potato glucose (PG) agar slopes in screw-cap bottles at $26^{\circ}$. Subcultures were made periodically by transferring large numbers of conidia to agar slopes. Liquid cultures were inoculated with $2 \%$ of their volume of a heavy conidial suspension (about $10^{6}$ conidia $/ \mathrm{ml}$.), using a conidial suspension from 7-day cultures. 
For experimental work the culture medium used was: Oxoid malt extract, 8 g.; yeast extract $3 \mathrm{~g}$.; proteose peptone $5 \mathrm{~g}$.; glucose $10 \mathrm{~g}$.; distilled water to $1 \mathrm{l}$. Samples $(25 \mathrm{ml}$.) of this liquid were added to $100 \mathrm{ml}$. conical flasks, plugged with non-absorbent cottonwool and sterilized (15 min., $15 \mathrm{lbs}$.). Flasks were incubated at $26^{\circ}$ for 4 days on a shaking machine operating at $200 \mathrm{rev} . / \mathrm{min}$. Test compounds were added to the flasks before sterilization.

Mycelial dry weights were determined by filtration by suction through previously weighed Whatman no. 1 filter paper, drying the mycelial mat for $4 \mathrm{hr}$ at $125^{\circ}$, cooling in a desiccator, and reweighing. Corrections were made for filter-paper weight lost on drying (about $5 \%$ ). The results expressed as $\mathrm{mg}$. dry-wt. mycelium.

Enzyme extraction. Mycelium for enzyme studies was grown in static liquid culture for $48 \mathrm{hr}$ at $26^{\circ}$. The culture medium was removed by suction filtration, and the mycelium rinsed in tap water and blotted dry.

The mitochondrial preparation was isolated by grinding mycelium with twice its weight of sand in a chilled mortar with a solution containing $0.6 \mathrm{M}$-sucrose $+\mathbf{0 . 2}$ M-tris buffer +0.005 M-ethylenediaminetetracetic acid (EDTA) +0.01 м $\mathrm{K}_{2} \mathrm{HPO}_{4}$ previously adjusted to $\mathrm{pH} \mathbf{7 \cdot 8}$ with $\mathrm{NaOH}$. The homogenate was passed through several layers of moist butter muslin and clarified by centrifugation at $1500 \mathrm{~g}$ for $10 \mathrm{~min}$. in an M.S.E. 'High Speed 17' refrigerated centrifuge, to remove coarse cell debris and nuclei. The mitochondrial preparation was then sedimented from the supernatant fluid by centrifugation at $20,000 \mathrm{~g}$ for $30 \mathrm{~min}$., and the deposit was re-suspended in a small volume of $0.4 \mathrm{M}$-sucrose in $0.05 \mathrm{M}$-phosphate buffer (pH 7.8).

Manometric assay of enzyme activities. Gaseous exchange was measured by the direct method of Warburg. Oxygen uptake was done in flasks containing $0.2 \mathrm{ml}$. of $6 \mathrm{~N}-\mathrm{KOH}$ in the centre wells to absorb the $\mathrm{CO}_{2}$ evolved. The mycelial dises used for respiratory studies were obtained from mycelium grown at $26^{\circ}$ for $48 \mathrm{hr}$. The discs ( $1 \mathrm{~cm}$. diameter) were washed in tap water, blotted free from excess water and added to the main compartment of the flask containing $2.0 \mathrm{ml}$. 0.1 M-phosphate buffer (pH 6.0). Test compounds in aqueous solution were added in samples of $0.2 \mathrm{ml}$. After all additions had been made, the total volume of the reaction mixture was brought to 3.0 $\mathrm{ml}$. by adding distilled water. The gas phase was air; all measurements were made at $30^{\circ}$.

The reaction mixtures for the manometric determination of succinate oxidase activity and component electron transfer reactions are given below. The reactions were done at $30^{\circ}$ after an equilibration period of $5 \mathrm{~min}$. and the oxygen uptake measured during $20 \mathrm{~min}$. Where the oxygen uptake was due to autoxidation of the reduced methylene blue or phenazine methosulphate to $\mathrm{H}_{2} \mathrm{O}_{2}$, the rates were halved to make them directly comparable with those of succinate oxidase. Cytochrome oxidase was measured according to Mackler \& Green (1956).

Succinate oxidase. $0.06 \mathrm{M}-\mathrm{KH}_{2} \mathrm{PO}_{4}+\mathrm{Na}_{2} \mathrm{HPO}_{4}$ buffer (pH 7.5), 0.03 м-sodium succinate, $9.5 \times 10^{-5} \mathrm{M}$-cytochrome $c$ and 2-3 $\mathrm{mg}$. mitochondrial protein.

Succinate-methylene blue reductase. As for succinate oxidase except substituting cytochrome $c$ with $1.6 \mathrm{mM}$-methylene blue and $1.7 \mathrm{mM}-\mathrm{KCN}$ to inhibit cytochrome oxidase.

Succinate-methylene blue reductase mediated by ubiquinone. As for succinatemethylene blue reductase $+3 \times 10^{-5} \mathrm{M}$-ubiquinone in $0.1 \mathrm{ml}$. ethanolic solution. The addition of the ubiquinone resulted in a 3- to 5-fold increase in oxygen uptake. 
Succinate-methylene blue reductase mediated by phenazine methosulphate. As for succinate-M.B. reductase +4 mM-phenazine methosulphate.

Succinate-phenazine methosulphate reductase. As for succinate-methylene blue reductase except replacing methylene blue with $4 \mathrm{~mm}$-phenazine methosulphate.

Spectrophotometric assays of enzyme activities. All assays were run at $30^{\circ}$ for 2 min. Rates were corrected from blank determinations done in the absence of substrate.

Succinate-cytochrome c reductase. $20 \mu$ moles sodium succinate were added to a reaction mixture containing: $0 \cdot 1-0 \cdot 3 \mathrm{mg}$. mitochondrial protein; $100 \mu$ moles$\mathrm{KH}_{2} \mathrm{PO}_{4}+\mathrm{K}_{2} \mathrm{HPO}_{4}$ buffer $(\mathrm{pH} 7 \cdot 4) ; 0.1 \mathrm{ml} .1 \%(\mathrm{w} / \mathrm{v})$ cytochrome $c ; 10 \mu$ moles $\mathrm{KCN}$ in a total volume of $3 \mathrm{ml}$. The rate of oxidation of succinate by cytochrome $c$ was determined by following the reduction of the cytochrome $c$ by the increase in extinction at $550 \mathrm{~m} \mu$.

Nicotinamide adenine dinucleotide $\left(\mathrm{NADH}_{2}\right)$ oxidase. $0 \cdot 2 \mu \mathrm{moles} \mathrm{NADH}_{2}$ was added to a reaction mixture containing $0.5-1.0 \mathrm{mg}$. mitochondrial protein, in $100 \mu$ moles $\mathrm{KH}_{2} \mathrm{PO}_{4}-\mathrm{K}_{2} \mathrm{HPO}_{4}$ buffer, $\mathrm{pH} 7 \cdot 4$. The reaction was followed by measuring the decrease in extinction at $340 \mathrm{~m} \mu$.

$\mathrm{NADH}_{2}$-cytochrome c reductase. As for succinate-cytochrome $c$ reductase with the exception that $0.2 \mu$ moles $\mathrm{NADH}_{2}$ replaced the sodium succinate.

In all assays enzyme activity was proportional to the amount of enzyme added. Protein concentrations of mitochondrial preparations were determined by the method of Ma \& Zuazaga (1942).

\section{RESULTS \\ Effect of 4-chloro-2-methylphenoxy butyric acid (MCPB) and 4-chloro-2-methylphenoxyacetic acid (MCPA) on mycelial growth}

The results in Fig. 1 show the effect of MCPB and MCPA on the growth of Aspergillus niger. In each case there was a stimulation of growth at low concentrations and an inhibition of growth at higher concentrations. A similar growth pattern was obtained when conidiospores were allowed to germinate for $24 \mathrm{hr}$ before the addition of the phenoxy acids. This would suggest that the stimulatory/ inhibitory effect of the compounds was being exerted against mycelial growth rather than on spore germination.

\section{Effect of $M C P B$ and $M C P A$ on endogenous and mitochondrial respiration}

When mycelial discs were incubated with different concentrations of the substituted phenoxy acids there was a progressive decrease with time in endogenous respiration (Table 1). At the highest concentration of MCPB $\left(5 \times 10^{-3} \mathrm{M}\right)$ there was marked inhibition of endogenous respiration after only $30 \mathrm{~min}$. of incubation. At this concentration prolonged periods of incubation resulted in complete inhibition of respiration. At the highest concentration of MCPA tested $\left(5 \times 10^{-3} \mathrm{M}\right)$ and an incubation period of $20 \mathrm{hr}$ the maximum inhibition was $52 \%$.

Mitochondrial preparations had considerable succinate oxidase and $\mathrm{NADH}_{2}$ oxidase activities. Both oxidases were sensitive to potassium cyanide, and succinate oxidase to malonate. For inhibitor studies mitochondrial preparations and the substituted phenoxy acids were incubated at $2^{\circ}$ for $30 \mathrm{~min}$. before measurement 
of enzyme activity. The oxidations of succinate and $\mathrm{NADH}_{2}$ were inhibited by both compounds, though in each case the inhibition by MCPB was much greater than by MCPA (Table 2). The inhibitory effect of low concentrations of MCPB $\left(5 \times 10^{-4} \mathrm{M}\right)$ could be enhanced by prolonged incubation with enzyme preparations.

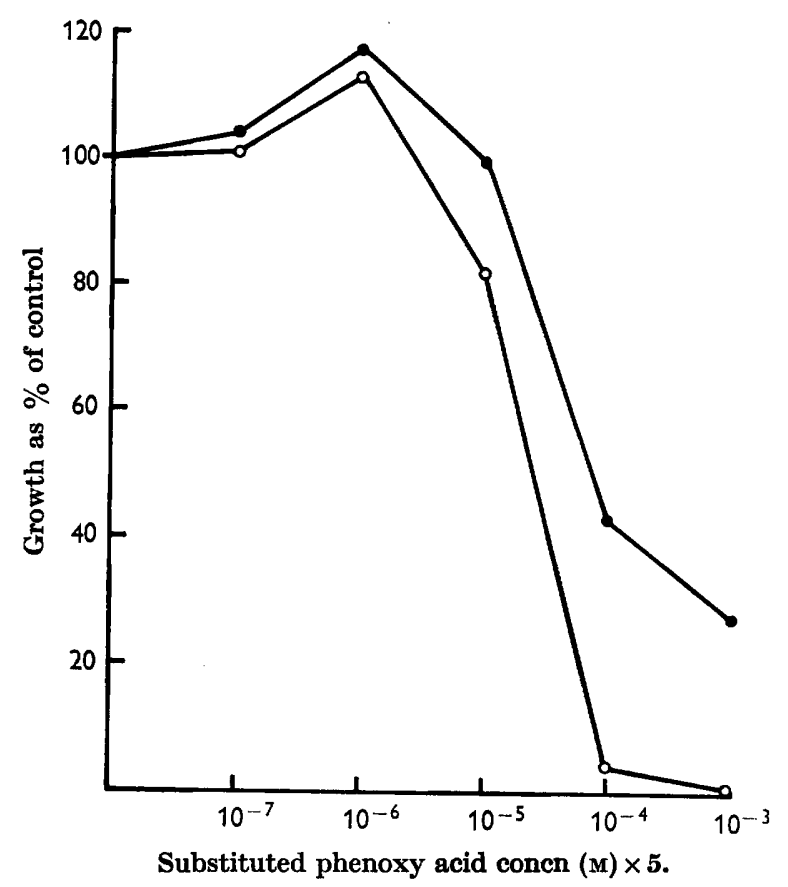

Fig. 1. The effect of 4-chloro-2-methylphenoxybutyric acid (MPCB) and 4-chloro-2methylphenoxyacetic acid (MCPA) on the growth of Aspergillus niger. Cultures were grown under shaking conditions for 4 days at $26^{\circ}$. Growth was measured as mycelial dry weight and results expressed as percentage of controls which did not contain MCPB or MCPA. (O), MCPA; (O), MCPB.

Table 1. The effect of 4-chloro-2-methylphenoxyacetic acid (MCPA), and 4-chloro2-methylphenoxybutyric acid (MCPB), on endogenous respiration of mycelial discs of Aspergillus niger

\begin{tabular}{|c|c|c|c|c|c|c|}
\hline \multirow{2}{*}{$\begin{array}{c}\text { Incubation } \\
\text { period } \\
\text { (hr) }\end{array}$} & \multicolumn{3}{|c|}{$\operatorname{MCPB}(\mathbf{M})$} & \multicolumn{3}{|c|}{ MCPA (M) } \\
\hline & $5 \times 10^{-5}$ & $5 \times 10^{-4}$ & $5 \times 10^{-3}$ & $5 \times 10^{-5}$ & $5 \times 10^{-4}$ & $5 \times 10^{-3}$ \\
\hline 0.5 & $\mathbf{0}$ & $\mathbf{0}$ & 35 & $\mathbf{0}$ & $\mathbf{0}$ & $\mathbf{0}$ \\
\hline $\mathbf{2}^{*}$ & 0 & 15 & 85 & o & 0 & 10 \\
\hline $20 *$ & 27 & 52 & 100 & $\mathbf{0}$ & $\mathbf{0}$ & 50 \\
\hline
\end{tabular}

\section{Effect of MCPB and MCPA on the component electron transport enzymes}

The component enzymes of the electron transport chain are known to be an integral part of the inner mitochondrial membrane and for this reason it is difficult to test the inhibitors against individual enzymes. This difficulty can be partially overcome by the use of artificial electron acceptors such as methylene blue, phena- 


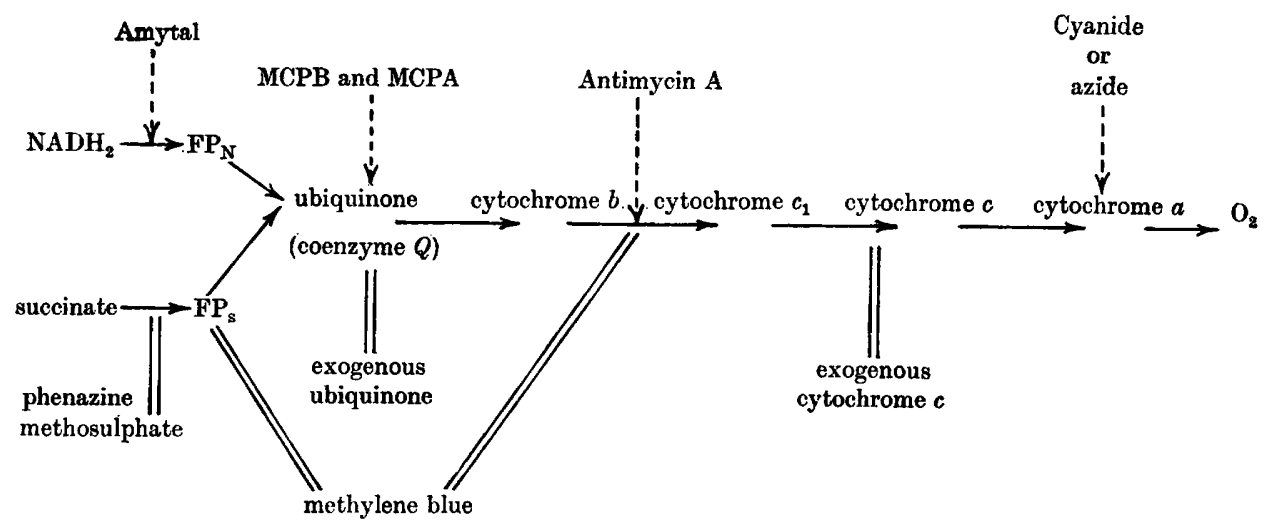

Fig. 2. A generalized scheme of electron transport. The full arrows show direction taken by the two reducing equivalents from substrate to oxygen. The broken arrows show the point of action of inhibitors. Double lines indicate regions at which artificial electron acceptors can participate in the electron flow. Abreviations: $\mathbf{N A D H}_{2}$, reduced nicotinamide adenine dinucleotide; $\mathbf{F P}_{\mathrm{s}}$ succinic dehydrogenase flavoprotein; $\mathbf{F P}_{\mathrm{N}}$, nucleotide dehydrogenase flavoprotein.

Table 2. Effect of 4-chloro-2-methylphenoxybutyric acid (MCPB), and 4-chloro-2methylphenoxyacetic acid (MCPA) on the respiratory oxidases of mitochondria from Aspergillus niger

Mitochondria and the substituted phenoxy acids were incubated at $2^{\circ}$ for $30 \mathrm{~min}$. before assaying activity.

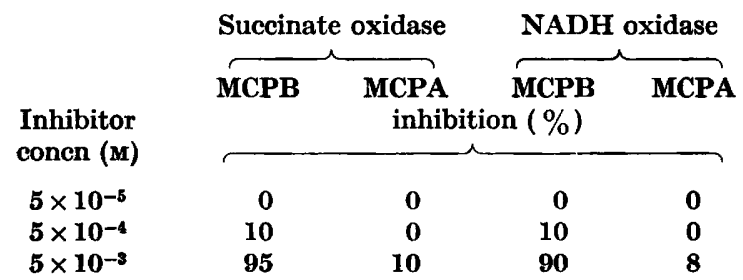

zine methosulphate, ubiquinone (Co. Q) and cytochrome $c$ to tap into the respiratory chain, and in this way to measure electron flow over known sections of it. In this way the approximate site of action of an inhibitor can be located. The use of methylene blue as a hydrogen acceptor in the manometric assay of the succinic dehydrogenase complex of mitochondrial preparations was described by Slater (1949). The dye appears to be a relatively inefficient acceptor since its rate of reduction is only a small fraction of the succinate oxidase rate. Methylene-blue reduction is greatly increased when other electron acceptors such as phenazine methosulphate or ubiquinone are also present in the reaction system. It is considered that the main site of action of methylene blue is between the succinate flavoprotein and the antimycin A-sensitive region. In this way it overlaps on to the common pathway of succinate oxidase and $\mathrm{NADH}_{2}$ oxidase (Fig. 2).

The results of the experiments on the effect of the substituted phenoxy acids on the component enzymes of succinate oxidase and $\mathrm{NADH}_{2}$ oxidase are shown in Table 3. These results suggest that there are possibly two sites of action of the compounds: 
one is before the site of action of phenazine methosulphate (about $25 \%$ inhibition); the second between the site of action of phenazine methosulphate and methylene blue (about $85 \%$ of residual activity).

Table 3. Effect of 4-chloro-2-methylphenoxybutyric acid (MCPB) and 4-chloro-2methylphenoxyacetic acid (MCPA), on the component enzymes of the succinate oxidase and $\mathrm{NADH}_{2}$ oxidase systems of Aspergillus niger.

Inhibitor concentration in each case was $5 \times 10^{-3} \mathrm{M}$.

Succinate oxidase

Enzyme system

Succinate-methylene blue reductase

Succinate-methylene blue reductase (mediated by ubiquinone)

Succinate-methylene blue reductase (mediated by phenazine methosulphate)

Succinate-phenazine methosulphate reductase

Succinate-cytochrome $c$ reductase

Cytochrome oxidase

$\mathrm{NADH}_{2}$ oxidase

$\mathrm{NADH}_{2}$-cytochrome $c$ reductase

$\overbrace{90}^{\begin{array}{r}\text { MCPB } \\ \text { Inhibition (\%) }\end{array}} \begin{array}{rr}\begin{array}{r}\text { MCPA } \\ 85\end{array} & 10 \\ 70 & 8 \\ 25 & 5 \\ 20 & 0 \\ 80 & 10 \\ 0 & 0 \\ 85 & 10 \\ 65 & 8\end{array}$

\section{DISCUSSION}

The effects of the two substituted phenoxy acids on the growth of Aspergillus niger show that each compound stimulated growth at low concentrations and inhibited at higher concentrations. The stimulation of growth by MCPB may be due to the presence of a $\beta$-oxidizing system within the fungus which converts the butyric to the active acetic homologue. Abundant evidence has accumulated which substantiates the $\beta$-oxidation pathway for fatty acid degradation by many microorganisms. The actinomycete Nocardia opaca can bring about the $\beta$-oxidation of $\omega$-phenoxyalkanecarboxylic acids (Webly, Duff \& Farmer, 1955), while $A$. niger and Sclerotinia laxa can degrade $\omega$-(2-naphthoxy)- $n$-alkylcarboxylic acid by $\beta$ oxidation (Byrde, Harris \& Woodcock, 1956; Byrde \& Woodcock, 1958).

The results in Tables 1-3 indicate that the inhibitory effect of the higher concentrations of the substituted phenoxy acids on the growth of Aspergillus niger were paralleled by a corresponding inhibition of the normal respiratory processes. Endogenous respiration was progressively inhibited with prolonged incubation with the compounds, and in a similar manner the essential components of the respiratory electron transport chain (succinate oxidase, $\mathrm{NADH}_{2}$ oxidase) were also inhibited. In all cases the degree of inhibition was always greater with MCPB than with an equimolar concentration of MCPA.

Since the relative inhibition of succinate oxidase and $\mathrm{NADH}_{2}$ oxidase was approximately the same, it is logical to consider that the main site of inhibition of the electron transport occurs at some point common to both electron pathways. Furthermore, the high degree of inhibition of succinate-methylene blue reductase implies that this inhibition occurs between the flavoprotein and antimycin A-sensitive area of the respiratory chain.

There is now much evidence which suggests that ubiquinone is a functional component of the mitochondrial respiratory chain, occupying a position on the oxygen side of the $\mathrm{NADH}_{2}$ and succinate flavoproteins and on the substrate side of cyto- 
chrome $c$ (Redfearn, 1961 $a$; Hatefi, 1963). Ubiquinone is widely distributed in micro-organisms and readily undergoes oxidation and reduction (Lester \& Crane, 1959; Morton, 1961; Crane, 1961; Brodie, 1961; Lavate, Dyer, Springer \& Bentley, 1962; Osnitskaya, Threlfall \& Goodwin, 1964). In the present study it has been found that ubiquinone can be used to mediate the reaction between the respiratory chain and methylene blue. This stimulation of succinate-methylene blue reduction by exogenous ubiquinone is generally considered to be due to a direct reaction with the flavoproteins or the complex which may be designated ubiquinone reductase (Redfearn, 1961b). In the presence of MCPB and MCPA this ubiquinone mediated electron transport in Aspergillus niger was inhibited 70 and $8 \%$, respectively. Thus it would appear that the main site of inhibition of the substituted phenoxy acids is at that part of the respiratory chain which involves ubiquinone, perhaps the enzyme complex ubiquinone reductase. There may also be other minor sites of action before and beyond this point since both succinate oxidase and $\mathrm{NADH}_{2}$ oxidase were inhibited to a greater extent than was the ubiquinone mediated succinate-methylene blue reduction.

The authors thank Miss Mary Sweeney and Miss Anne Campbell for technical assistance. This work was partly supported by the grant of a Scholarship to one of us (J.L.S.) by May and Baker Ltd.

\section{REFERENCES}

Brodie, A. F. (1961). Vitamin $K$ and other quinones as coenzymes in oxidative phosphorylation in bacterial systems. Fed. Proc. $20,989$.

Byrde, R. J. W. \& Woodcock, D. (1958). Fungal detoxication. III. The metabolism of $\omega$-(2-naphthyloxy)-n-alkylcarboxylic acids by Sclerotinia laxa. Biochem. J. 69, 19.

Byrde, R. J. W., Harris, J. F. \& Woodcock, D. (1956). The metabolism of $\omega$-(naphthyloxy)-n-alkylearboxylic acids by Aspergillus niger. Biochem. J. 64, 154 .

Crane, F. L. (1961). Quinones in Electron Transport. In Ciba Foundation Symposium. Ed. by G. E. W. Wolstenholme and C. M. O'Connor, p. 36.

Fawcett, C. H., Wain, R. L. \& Wightman, F. (1960). Metabolism of 3-indolylalkane carboxylic acids and their amides, nitriles and methyl esters in plant tissues. Proc. Roy. Soc. B, 152, 281.

HAtEFi, Y. (1963). Coenzyme Q (Ubiquinone). Advanc. Enzymology, 25, 275.

Lavate, W. V., Dyer, J. R., Springer, C. M. \& Bentley, R. (1962). A new naturally occurring member of the coenzyme group; tetrahydro-coenzyme $Q_{10} . J$. biol. Chem. 237, 2715.

Lester, R. L. \& Crane, F. L. (1959). The natural occurrence of Coenzyme $Q$ and related compounds. J. biol. Chem. 234, 2169.

MA, T. S. \& ZuAZAGA, G. (1942). Micro-Kjeldahl determination of nitrogen. Ind. engng Chem. 14, 280.

Mackler, B. \& Green, D. E. (1956). Studies on the electron transport. 11. On the opening phenomenon. Biochim. biophys. Acta, 21, 1.

Morton, R. A. (1961). Quinones in Electron Transport. In Ciba Foundation Symposium. Ed. by G. E. W. Wolstenholme and C. M. O'Connor, p. 5.

Osnitskaya, L. K., Threlfall, D. R. \& Goodwin, T. W. (1964). Ubiquinone-40 and vitamin $\mathrm{K}_{\mathbf{2}}(4,0)$ in Chromatium vinosum. Nature, Lond. 204, 80.

Redfearn, E. R. (1961 a). Quinones in Electron Transport. In Ciba Foundation Symposium. Ed. by G. E. W. Wolstenholme and C. M. O'Connor, p. 346.

REDfearn, E. R. $(1961 b)$. The role of ubiquinone (coenzyme $Q$ ) and its homologues in mediating the reduction of methylene blue by succinate in heart-muscle preparations. Biochim. biophys. Acta. 53, 581. 
Shennan, J. L. \& Fletcher, W. W. (1965). The growth in vitro of micro-organisms in the presence of substituted phenoxyacetic and phenoxy-butyric acids. Weed Res. 5, 266.

Stater, E. C. (1949). A comparative study of the succinate dehydrogenase-cytochrome system in heart muscle preparations of kidney. Biochem. J. 45, 1.

WaIN, R. L. (1955). A new approach to selective weed control. Ann. appl. Biol. 42, 151.

WaIN, R. L. (1957). Selective weed control with MCPB. Agriculture, 63, 575.

Webley, D. M., DufF, R. B. \& Farmer, V. C. (1955). $\beta$-Oxidation of fatty acids by Nocardia opaca. J. gen. Microbiol. 13, 361. 